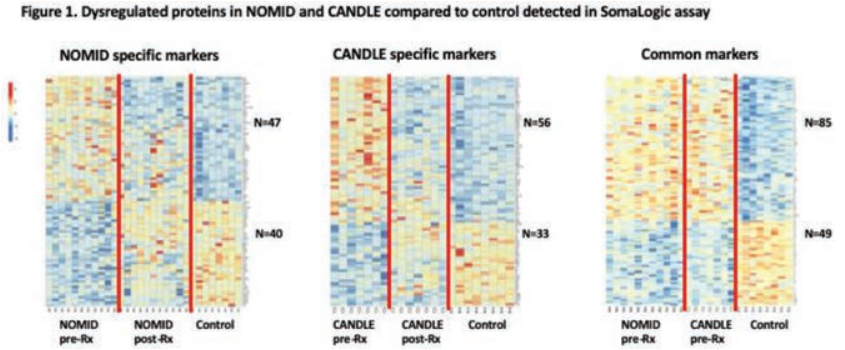

Acknowledgments: This work was supported by Intramural Research at National Institute of Allergy Immunology and Infectious Diseases of National Institutes of Health, Bethesda, Maryland, the Center of Human Immunology and was approved by the IRB.

Disclosure of Interests: None declared

DOI: 10.1136/annrheumdis-2020-eular.351

\section{OP0287 A MACHINE LEARNING APPROACH FOR PRECISION STRATIFICATION OF JUVENILE-ONSET SLE}

G. Robinson ${ }^{1}$, J. Peng ${ }^{1}$, P. Dönnes ${ }^{1}$, L. Coelewij ${ }^{1}$, M. Naja ${ }^{1}$, A. Radziszewska ${ }^{1}$, C. Wincup ${ }^{1}$, H. Peckham ${ }^{1}$, D. Isenberg ${ }^{1}$, Y. Ioannou ${ }^{1}$, I. Pineda Torra ${ }^{1}$,

C. Ciurtin ${ }^{1}$, E. Jury ${ }^{1}$ on behalf of The Jury Group and The Centre for Adolescent Rheumatology Versus Arthritis at UCL, UCLH and GOSH. ${ }^{1}$ University College London, London, United Kingdom

Background: Juvenile-onset systemic lupus erythematosus (JSLE) is a complex and heterogeneous disease characterised by diagnosis and treatment delays. An unmet need exists to better characterise the immunological profile of JSLE patients and investigate its links with the disease trajectory over time.

Objectives: A machine learning (ML) approach was applied to explore new diagnostic signatures for JSLE based on immune-phenotyping data and stratify patients by specific immune characteristics to investigate longitudinal clinical outcome.

Methods: Immune-phenotyping of $28 \mathrm{~T}$-cell, B-cell and myeloid-cell subsets in 67 age and sex-matched JSLE patients and 39 healthy controls (HCs) was performed by flow cytometry. A balanced random forest (BRF) ML predictive model was developed (10,000 decision trees). 10-fold cross validation, Sparse Partial Least Squares-Discriminant Analysis (sPLS-DA) and logistic regression was used to validate the model. Longitudinal clinical data were related to the immunological features identified by ML analysis.

Results: The BRF-model discriminated JSLE patients from healthy controls with $91 \%$ prediction accuracy suggesting that JSLE patients could be distinguished from $\mathrm{HCs}$ with high confidence using immunological parameters. The top-ranked immunological features from the BRF-model were confirmed using sPLS-DA and logistic regression and included CD19+ unswitched memory B-cells, naïve B-cells, CD $14^{+}$monocytes and total $\mathrm{CD} 4^{+}, \mathrm{CD} 8^{+}$and memory T-cell subsets.

K-mean clustering was applied to stratify patients using the validated signature. Four groups were identified, each with a distinct immune and clinical profile. Notably, $\mathrm{CD} 8^{+} \mathrm{T}$-cell subsets were important in driving patient stratification while B-cell markers were similarly expressed across the JSLE cohort. JSLE patients with elevated effector memory $\mathrm{CD}^{+} \mathrm{T}$-cell frequencies had more persistently active disease over time, and this was associated with increased treatment burden and prevalence of lupus nephritis. Finally, network analysis identified specific clinical features associated with each of the top JSLE immune-signature variables.

Conclusion: Using a combined ML approach, a distinct immune signature was identified that discriminated between JSLE patients and HCs and further stratified patients. This signature could have diagnostic and therapeutic implications. Further immunological association studies are warranted to develop data-driven personalised medicine approaches for JSLE.

Acknowledgments: Lupus UK, Rosetrees Trust, Versus Arthritis

Disclosure of Interests: George Robinson: None declared, Junjie Peng: None declared, Pierre Dönnes: None declared, Leda Coelewij: None declared, Meena Naja: None declared, Anna Radziszewska: None declared, Chris Wincup: None declared, Hannah Peckham: None declared, David Isenberg Consultant of: Study Investigator and Consultant to Genentech, Yiannis Ioannou: None declared, Ines Pineda Torra: None declared, Coziana Ciurtin Grant/research support from: Pfizer, Consultant of: Roche, Modern Biosciences, Elizabeth Jury: None declared DOI: 10.1136/annrheumdis-2020-eular.4167

\section{OP0288 \\ ANTI-IL1 TREATMENT IN COLCHICINE RESISTANT PEDIATRIC FMF PATIENTS-REAL LIFE DATA FROM THE HELIOS REGISTRY}

E. Sag ${ }^{1}$, F. Akal ${ }^{2}$, E. Atalay ${ }^{1}$, U. Kaya Akca ${ }^{1}$, S. Demir ${ }^{1}$, D. Demirel ${ }^{1}$, E. D. Batu', Y. Bilginer ${ }^{1}$, S. Özen ${ }^{1}{ }^{1}{ }^{1}$ Hacettepe University Faculty of Medicine, Pediatric Rheumatology, Ankara, Turkey; ${ }^{2}$ Hacettepe University, Computer Engineering, Ankara, Turkey

Background: FMF is a prototype of autoinflammatory diseases associated with excess IL1 production. Anti-IL1 treatments are the first-line alternatives in colchicine resistant/intolerant FMF patients.

Objectives: We aimed to investigate the efficacy and safety of anti-IL1 treatment in pediatric FMF patients in our local (HELIOS) registry.

Methods: HELIOS (Hacettepe univErsity eLectronlc research fOrmS) is a webbased biological drug registry for pediatric rheumatology patients (helios.hacettepe.edu.tr). Data were recorded at biological treatment onset (month 0), at month 6 and yearly thereafter in patients. We have analysed the clinical features, disease activity parameters, treatment responses and safety outcomes in FMF patients treated with anti-IL1 agent.

Results: Forty pediatric FMF patients were included to the study group (67\% female).

Thirty-four patients received continous anti-IL1 treatment. The mean age at the start of the colchicine was $5.55 \pm 3.87$ years. Age at onset of the anti-IL1 treatment was $11.47 \pm 5.41$ with a mean follow-up duration of $3.87 \pm 1.96$ years. Apart from two patients, all of them had biallelic exon-10 mutations.

We have also given anti-IL1 treatment on an on-demand basis in six adolescent patients. Five of them were having very severe attacks during menstrual periods and one was having attacks during extreme stress periods along with very high CRP levels. The quality of life has markedly improved and these patients no longer reveal any CRP elevation.

Anakinra was used as the first-line anti-IL1 treatment. During the last visit, six patients were treated with anakinra and 28 patients were treated with canakinumab. Anti-IL1 treatment decreased the CRP levels, number and severity of the attacks. (Figure 1.) There were three hospitalizations reported due to mild infections. Eleven patients had local skin reactions, two patients had leukopenia with anakinra and one patient had thrombocytopenia with canakinumab. We have discontinued anti-IL1 treatment until the cytopenia subsided. We have switched to on-demand therapy in one patient, started the same treatment and gradually increased the dose in the other two patients. There were no malignancy or other severe adverse reactions.
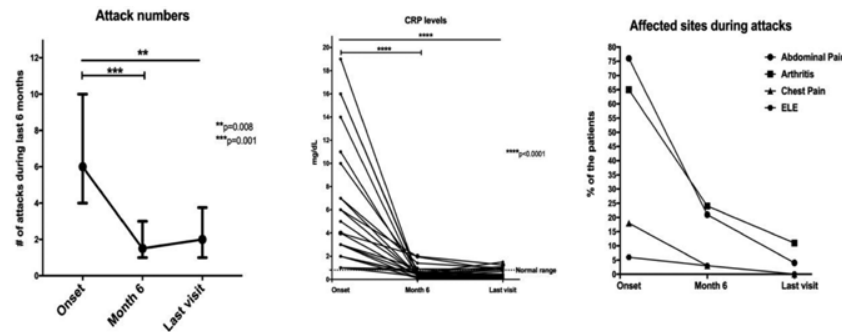

Figure 1.

Conclusion: Anakinra and canakinumab are efficient and safe alternatives in colchicine resistant and intolerant pediatric FMF patients. We also for the first time, report on-demand use of anti-IL1 in pediatric FMF patients. We sugges that on-demand treatment should be considered under certain circumstances where the trigger is known and short-lasting (such as menstruation and periods of extreme stress)

Acknowledgments: Authors would like to thank Elif Arslanoglu Aydin, Armagan Keskin, Kubra Yuksel and Emil Aliyev for their contribution to the HELIOS registry Disclosure of Interests: Erdal Sag Grant/research support from: Novartis and SOBI financially supported the HELIOS registry during the establishment of infrastructure, Fuat Akal Grant/research support from: Novartis and SOBI financially supported the HELIOS registry during the establishment of infrastructure, Erda Atalay Grant/research support from: Novartis and SOBI financially supported the HELIOS registry during the establishment of infrastructure, Ummusen Kaya Akca Grant/research support from: Novartis and SOBI financially supported the HELIOS registry during the establishment of infrastructure, Selcan Demir Grant/ research support from: Novartis and SOBI financially supported the HELIOS registry during the establishment of infrastructure, Dilara Demirel Grant/research support from: Novartis and SOBI financially supported the HELIOS registry during the establishment of infrastructure, Ezgi Deniz Batu Grant/research support from: Novartis and SOBI financially supported the HELIOS registry during 
the establishment of infrastructure, Yelda Bilginer Grant/research support from: Novartis and SOBI financially supported the HELIOS registry during the establishment of infrastructure, Seza Özen Consultant of: Novartis, Pfizer, Speakers bureau: SOBI, Novartis

DOI: 10.1136/annrheumdis-2020-eular.1313

\begin{tabular}{|l|l}
\hline OP0290 & EMAPALUMAB (ANTI-INTERFERON-GAMMA \\
MONOCLONAL ANTIBODY) IN PATIENTS WITH \\
MACROPHAGE ACTIVATION SYNDROME (MAS) \\
COMPLICATING SYSTEMIC JUVENILE IDIOPATHIC \\
ARTHRITIS (SJIA)
\end{tabular}

F. De Benedetti ${ }^{1}$, P. Brogan ${ }^{2}$, C. Bracaglia ${ }^{1}$, M. Pardeo ${ }^{1}$, G. Marucci ${ }^{1}$, E. Sacco ${ }^{1}$, D. Eleftheriou' ${ }^{2}$, C. Papadopoulou' ${ }^{2}$, A. Grom ${ }^{3}$, P. Quartier ${ }^{4}$, R. Schneider ${ }^{5}$, P. Jacqmin ${ }^{6}$, R. Frederiksen ${ }^{7}$, M. Ballabio ${ }^{7}$, C. De Min ${ }^{7}{ }^{1} / R C C S$ Ospedale Pediatrico Bambino Gesù, Rheumatology, Rome, Italy; ${ }^{2}$ UCL Institute of Child Health, and Great Ormond Street Hospital NHS Foundation Trust, Section Head Infection, Immunology, and Rheumatology, London, United Kingdom; ${ }^{3}$ Cincinnati Children's Hospital, Division of Rheumatology, Cincinnati, United States of America; ${ }^{4}$ Paris-Descartes University, IMAGINE Institute, RAISE Reference Centre, Pediatric Immuno-Hematology and Rheumatology Unit, Necker Hospital, Assistance Publique-Hôpitaux de Paris, Paris, France; ${ }^{5}$ The Hospital for Sick Children, Department of Pediatrics, Division of Rheumatology, Toronto, Canada; ${ }^{6}$ MnS Modelling and Simulation, Dinant, Belgium; ${ }^{7}$ Swedish Orphan Biovitrum AG (Sobi), Basel, Switzerland

Background: MAS is a severe complication of rheumatic diseases and occurs most frequently in patients with sJIA. Data from animal models and from observational studies in patients suggest that interferon gamma (IFNy) is a driver of the hyperinflammation and hypercytokinemia observed in MAS.

Objectives: To assess the pharmacokinetics, efficacy, and safety of intravenous (IV) infusions of emapalumab, a fully human anti-IFNY monoclonal antibody, in patients with MAS in the context of sJIA.

Methods: This ongoing, pilot, open-label, single-arm study (NCT03311854) includes patients with MAS (2016 ACR/EULAR criteria) on a background of confirmed, or high presumption of, SJIA, and with inadequate response to high-dose IV glucocorticoids. Emapalumab is initiated at $6 \mathrm{mg} / \mathrm{kg}$ (1 dose) and continued at $3 \mathrm{mg} / \mathrm{kg}$ twice weekly for a total of 4 weeks, or less upon achievement of complete response (CR). CR is defined as an absence of MAS clinical signs plus white blood cell and platelet counts above the lower limit of normal, LDH, AST and ALT $<1.5 \times$ upper limit of normal, fibrinogen $>100 \mathrm{mg} / \mathrm{dL}$, and ferritin decreased by $\geq 80 \%$ or to $<2,000 \mathrm{ng} / \mathrm{mL}$.

Results: We report preliminary data from the first 9 patients (median age [range] 11.6 [2.1-25.3] years) enrolled (7 in Europe and 2 in the USA). All patients had failed high-dose methylprednisolone, of which there were prior treatment failures from cyclosporin $A(n=4)$ and from anakinra $(n=4)$. Treatment with emapalumab resulted in rapid IFNY neutralization, as demonstrated by the decrease in CXCL9 levels (Figure 1), and subsequent deactivation of $T$ cells, as indicated by the decrease in sIL-2R levels. CR was achieved in all patients after a median of 23 (12-56) days. A progressive improvement in all clinical and laboratory parameters of MAS was observed (Table 1 and Figure 2). Glucocorticoids were tapered in all patients (median \% tapering $-92 \%$; range $-45 \%$ to $-98 \%$ at Week 8 ). Emapalumab infusions were well tolerated by all patients, with no discontinuation. CMV reactivation was reported in 1 patient as a serious event possibly related to emapalumab and resolved with antiviral treatment.

Table 1. Time to response for key clinical and laboratory parameters.

\begin{tabular}{lcc}
\hline Parameters & $\begin{array}{c}\text { Median baseline value } \\
\text { (range) }\end{array}$ & $\begin{array}{c}\text { Median days of } \\
\text { treatment (range) }\end{array}$ \\
\hline D-dimers to $<1000 \mathrm{mg} / \mathrm{L}$ & $12,480(550-89,552)$ & $15(1-49)$ \\
sIL-2R to $<2000 \mathrm{ng} / \mathrm{L}$ & $4596(1664-20,954)$ & $21(6-37)$ \\
Ferritin $<500 \mathrm{mg} / \mathrm{L}$ & $29,240(716-192,584)$ & $21(9-42)$ \\
Physician visual analog scale of MAS activity $\leq 1$ & $9.0(2-10)$ & $19(9-56)$ \\
$\begin{array}{l}\text { All MAS laboratory parameters within range } \\
\text { of CR }\end{array}$ & NA & $21(15-55)$ \\
All MAS parameters within range of CR & NA & $23(12-56)$ \\
Glucocorticoid tapering at $\leq 1$ mg/kg predniso- & NA & $42(16-50)$ \\
$\quad$ lone equivalent* & & \\
\hline
\end{tabular}

${ }^{*}$ Data incomplete for 1 patient

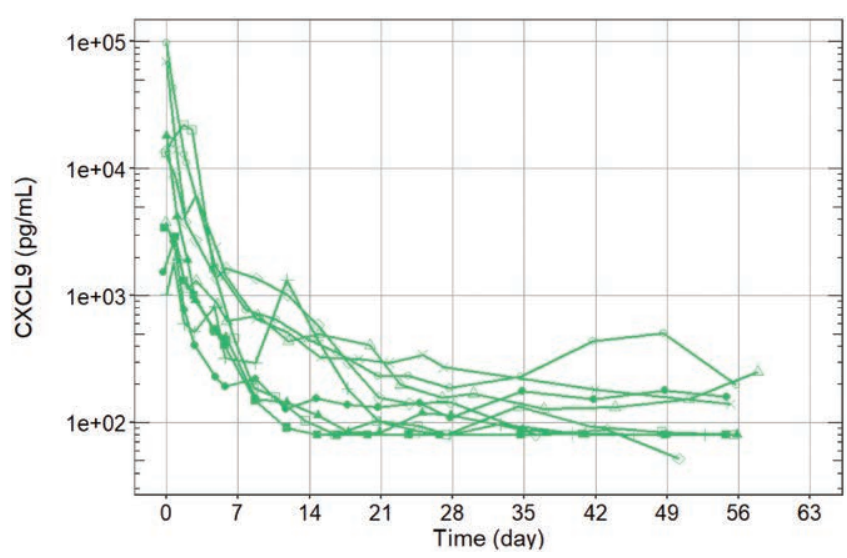

Figure 1. Rapid neutralization of IFNy. Each line represents an individual patient $(n=9)$.

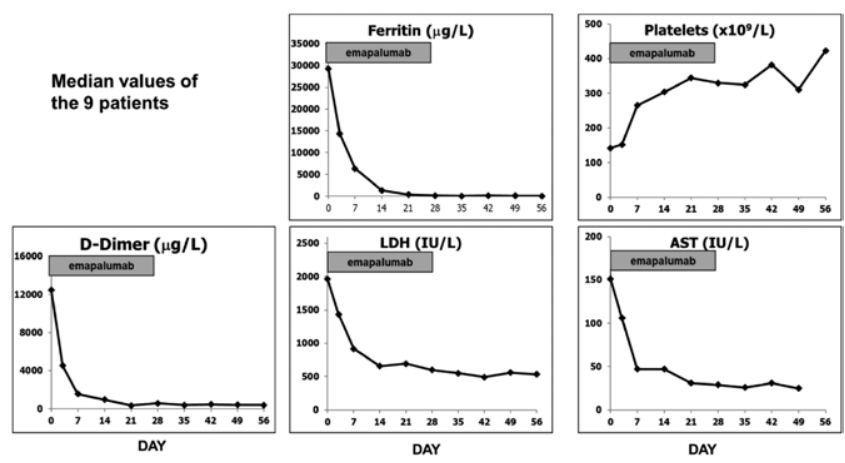

Figure 2. Ferritin levels and platelet counts over time.

Conclusion: Emapalumab administration led to rapid neutralization of IFNy and was efficacious in controlling MAS with a favorable safety profile. These results support the pathogenic role of IFNY in MAS/sJIA and the therapeutic value of IFNy neutralization in MAS patients who have failed standard of care.

Disclosure of Interests: Fabrizio De Benedetti Grant/research support from: AbbVie, Pfizer, Novartis, Novimmune, Sobi, Sanofi, Roche, Speakers bureau: AbbVie, Novartis, Roche, Sobi, Paul Brogan Grant/research suppor from: Sobi, Novartis, Roche, Chemocentryx, Consultant of: Roche, Sobi, Speakers bureau: Sobi, Roche, Novartis, UCB, Claudia Bracaglia: None declared, Manuela Pardeo: None declared, Giulia Marucci: None declared, Emanuela Sacco: None declared, Despina Eleftheriou Speakers bureau: Sobi, Charalampia Papadopoulou: None declared, Alexei Grom Grant/ research support from: Novartis, AB2Bio, Consultant of: Novartis, Pierre Quartier Consultant of: AbbVie, Chugai-Roche, Lilly, Novartis, Sanofi, Sobi, Speakers bureau: AbbVie, BMS, Chugai-Roche, Novartis, Pfizer, Sobi, Rayfel Schneider Grant/research support from: Roche, Novartis, Sobi, Pfizer Consultant of: Sobi, Novartis, Novimmune, Philippe Jacqmin Consultant of: Sobi, Rikke Frederiksen Employee of: Sobi, Maria Ballabio Employee of: Sobi, Cristina De Min Employee of: Sobi

DOI: 10.1136/annrheumdis-2020-eular.3169

\section{OP0291 TOFACITINIB FOR THE TREATMENT OF POLYARTICULAR COURSE JUVENILE IDIOPATHIC ARTHRITIS: RESULTS OF A PHASE 3, RANDOMISED, DOUBLE-BLIND, PLACEBO-CONTROLLED WITHDRAWAL STUDY}

N. Ruperto ${ }^{1}$, O. Synoverska ${ }^{1}$, T. Ting $^{2}$, C. Abud-Mendoza ${ }^{1}$, A. Spindler ${ }^{1}$, Y. Vyzhga ${ }^{1}$, K. Marzan ${ }^{2}$, V. Keltsev ${ }^{1}$, I. Tirosh ${ }^{1}$, L. Imundo $^{2}$, R. Jerath ${ }^{2}$, D. Kingsbury ${ }^{2}$, B. Sözeri ${ }^{1}$, S. Vora ${ }^{2}$, S. Prahalad ${ }^{2}$, E. Zholobova ${ }^{1}$, Y. Butbul Aviel $^{1}$, V. Chasnyk ${ }^{1}$, M. Lerman ${ }^{2}$, K. Nanda ${ }^{2}$, H. Schmeling ${ }^{2}$, H. Tory ${ }^{2}$, Y. Uziel ${ }^{1}$, D. O. Viola ${ }^{1}$, H. Posner ${ }^{3}$, K. Kanik ${ }^{4}$, A. Wouters ${ }^{3}$, C. Chang ${ }^{4}$, R. Zhang ${ }^{3}$, I. Lazariciu ${ }^{5}$, M. A. Hsu ${ }^{4}$, R. Suehiro ${ }^{6}$, A. Martini ${ }^{1}$, D. J. Lovell ${ }^{2}$, H. Brunner ${ }^{2}$ on behalf of PRINTO/PRCSG. ${ }^{1}$ PRINTO, Istituto Giannina Gaslini, Genova, Italy;

${ }^{2}$ PRCSG, Cincinnati Children's Hospital Medical Center, Cincinnati, OH, United States of America; ${ }^{3}$ Pfizer Inc, New York, NY, United States of America; ${ }^{4}$ Pfizer Inc, Groton, CT, United States of America; ${ }^{5}$ IQVIA, Montreal, QC, Canada; ${ }^{6}$ Pfizer Inc, Collegeville, PA, United States of America 